\title{
Non-Surgical Approach to Correct Skeletal Open-Bite Malocclusion in an Adult Patient Using Third Molar Intrusion Mechanics: A Clinical Case Report
}

\author{
Saima Nizar Hirji ${ }^{10}$ \\ ${ }^{1}$ Department of Orthodontics, The Dental Centre, Nairobi, Kenya \\ Eur J Gen Dent 2022;11:64-72.
}

\begin{abstract}
Address for correspondence Saima Nizar Hirji, BDS, MSC Orthodontics (Austria), The Dental Centre, Parkwest Office Suites, 8C, TRV Centre, 3rd Parklands, Nairobi - 41773-00100, Kenya (e-mail: saima.hirji@icloud.com).
\end{abstract}

Abstract
Keywords
- skeletal open bite
- temporary anchorage
devices
- maxillary molar
intrusion

Paradigm is shifting in the orthodontic world with the introduction of mini screw type of temporary anchorage devices (TADs). This clinical report shows treatment and 3year retention results of nonsurgical and extraction treatment in a 34-year-old female patient treated with maxillary molar intrusion mechanics and habit control. After 24 months of active orthodontic treatment, splendid outcomes were achieved. She presented with a chief complaint of problems in biting from her front teeth. She has a Class II skeletal and dental relationship with increased vertical proportions. Control of vertical dimension and producing autorotation of mandible were the key reasons to reduce facial convexity and improvement in profile. Treatment effects of 5 degrees of autorotation of mandible and $4 \mathrm{~mm}$ of maxillary molar intrusion were produced to correct pre-treatment anterior open bite of $5 \mathrm{~mm}$. Based on available clinical evidence, we suggest that TADs with composite buttons on molars can be used as a valuable tool to intrude molars including wisdom teeth, and help correct the skeletal open-bite with good control without buccal tipping.

\section{Introduction}

Around 28 to $38 \%$ of orthodontic treated patients are suffering from open-bite malocclusion. ${ }^{1}$ Various genetic and environmental contributing factors are involved in this type of malocclusion and it is presented as an overeruption of the maxillary molars. The complexity of malocclusion and time of treatment onset may result in open bite correction, with stability being more difficult to achieve. ${ }^{2}$ Habit control during and after fixed appliance removal and patient compliance in the use of retainers is also a crucial factor. Various treatment alternatives are available in the literature ranging from simple habit control to complex surgical intervention. It includes a palatal crib, high-pull headgear, orthodontic camouflage with posterior teeth extractions, vertical chin cup, box elastics, multi-loop archwires (MEAW), posterior bite blocks, functional appliances, orthognathic surgery, mini-implants, mini-plates, and magnets, etc. ${ }^{2-8}$

Paradigm is shifting in the orthodontic world with the introduction of mini screw type of temporary anchorage devices (TADs). Tiny screws can be implanted with an easy surgical procedure, increasing the potential for a better orthodontic outcome. Thus, it not only helps in anchorage demanding cases but also helps achieve control of tooth movement all in all three dimensions. A similar result could
DOI https://doi.org/ $10.1055 / \mathrm{s}-0042-1742358$. ISSN 2320-4753.

\section{(C) 2022. The Author(s).}

This is an open access article published by Thieme under the terms of the Creative Commons Attribution License, permitting unrestricted use, distribution, and reproduction so long as the original work is properly cited. (https://creativecommons.org/licenses/by/4.0/)

Thieme Medical and Scientific Publishers Pvt. Ltd., A-12, 2nd Floor, Sector 2, Noida-201301 UP, India 
be obtained with surgery although it would increase the overall cost of treatment, exposing patients to morbidity and side effects caused by surgical procedures.

This clinical report shows treatment and 3-year retention results of nonsurgical and extraction treatment in a 34-yearold female patient with the use of maxillary molar intrusion mechanics and habit control. After 24 months of active orthodontic treatment, splendid outcomes were achieved.

\section{Case Report}

\section{Diagnosis}

An Asian female, age 34 years and 10 months, had an anterior open bite with Class II skeletal malocclusion with insignificant medical history. Her chief complaint was "I have a problem in biting from front teeth and I do not like my smile." The tonguethrusting habit was noted during rest, swallowing, and while conversation. She has a bilaterally symmetrical face, a dolichocephalic skull shape, a convex soft tissue profile, an obtuse nasolabial angle, and incompetent procumbent lips (- Fig. 1). Adequate gingival exposure was noted on a smile. Intraoral and cast examinations (-Figs. 1 and $\mathbf{2}$ ) demonstrated a Class II div I incisors, Class 1 canine and molar relationship on the left side, and Class II canine and half unit class II molars on the right side. The upper midline was deviated $1.5 \mathrm{~mm}$ to right, while the lower midline coincided with the face. Overjet of $5 \mathrm{~mm}$, an open bite of $5 \mathrm{~mm}$, crowding of $-5 \mathrm{~mm}$ in upper and $-8 \mathrm{~mm}$ in the lower jaw were observed with 2 steps of occlusal planes, anterior and posterior. Bolton discrepancy of an overall mandibular excess of $2.7 \mathrm{~mm}$ and anterior tooth excess of $2.4 \mathrm{~mm}$ was measured. Gingival recession was observed on all anterior teeth in both jaws. The unilateral crossbite was observed on the left side in the segment of the upper left canine, first, and second premolars. During opening or closing of her jaws, no mandibular deviation or clicking noises were detected.

The panoramic radiograph ( - Fig. 3A) showed root resorption in lower anterior teeth and mild generalized bone loss around posterior teeth. Roots of upper molars were residing inside the maxillary sinus on the left side. All third molars have fully erupted.

The cephalometric analysis ( - Fig. 3B, - Table 1) showed a Class II skeletal relationship with a high-angle vertical growth pattern. Normal upper incisors and proclined lower incisors with no chin support and procumbent lower lips were seen.

The etiology of the open-bite malocclusion appeared to be a combination of hereditary and habitual factors.

\section{Treatment Objectives}

The goals were established to achieve correction in all transverse, vertical, and anteroposterior dimensions: ${ }^{1}$ improve facial attractiveness by reducing mentalis muscle strain and providing lips support and competency, ${ }^{2}$ control vertical dimension and produce autorotation of mandible to reduce facial convexity, ${ }^{4}$ control tongue thrust habit, ${ }^{5}$ create esthetic smile arc and fuller smile with controlled gum exposure, ${ }^{6}$ correct the constricted maxilla and unilateral crossbite, ${ }^{7}$
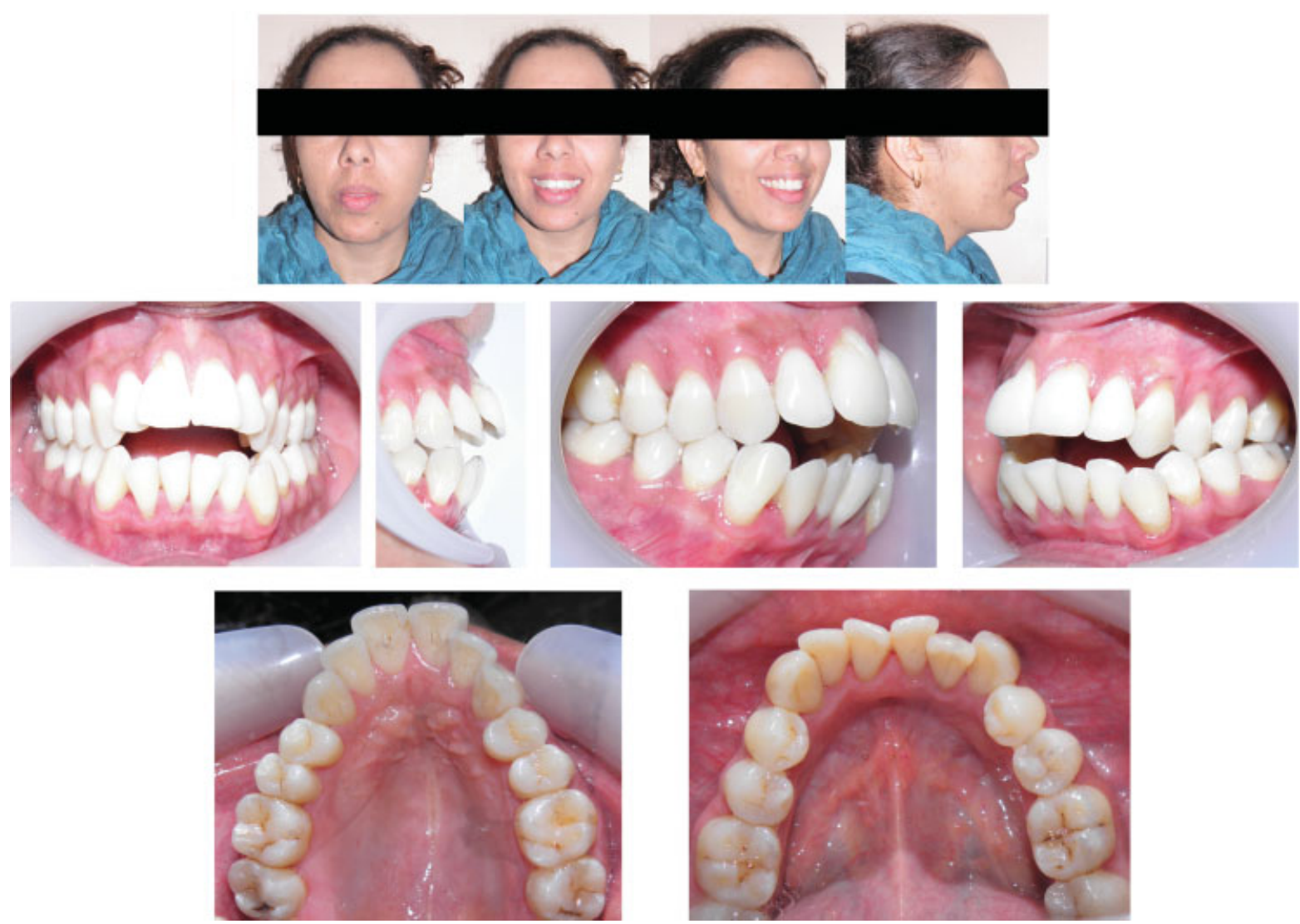

Fig. 1 Pretreatment facial and intraoral images. 
66 Skeletal Open-bite Malocclusion Correction Hirji et al.
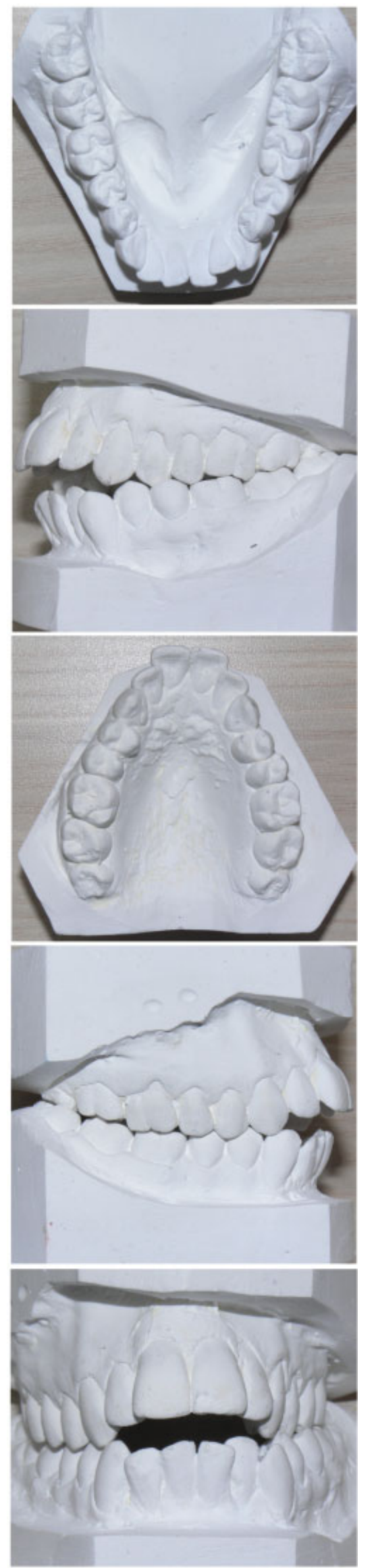

Fig. 2 Pretreatment cast images.

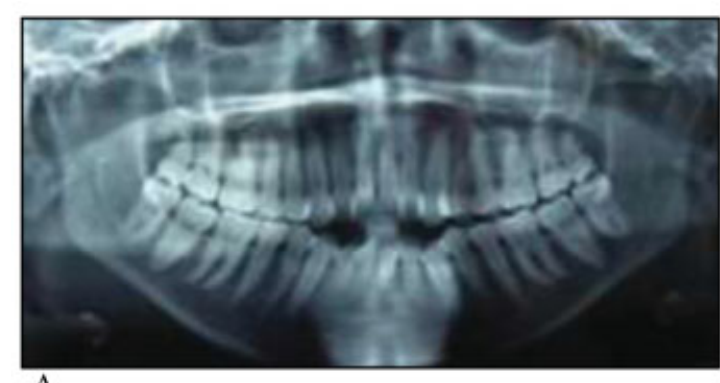

A

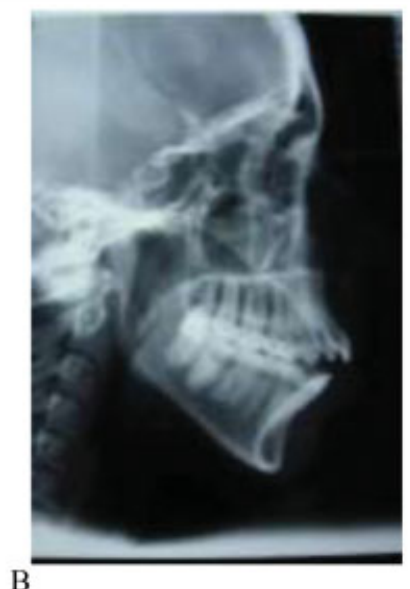

Fig. 3 Pretreatment panoramic (A) and cephalometric (B) radiographs.

Table 1 Cephalometric analysis

\begin{tabular}{|c|c|c|c|}
\hline Measurement & Norms & $\begin{array}{l}\text { Pre- } \\
\text { treatment }\end{array}$ & $\begin{array}{l}\text { Post- } \\
\text { treatment }\end{array}$ \\
\hline \multicolumn{4}{|l|}{ Sagittal analysis } \\
\hline SNB & $78 \pm 2$ & 68 & 70 \\
\hline ANB & $2 \pm 2$ & 9 & 9 \\
\hline Facial angle & $87 \pm 3$ & 81 & 81 \\
\hline Mac-A (mm) & $1 \pm 2$ & 0 & -1 \\
\hline Mac-Pog $(\mathrm{mm})$ & $-3 \pm 4$ & -19 & -12 \\
\hline Wits & $0 \pm 2$ & 0 & 2 \\
\hline \multicolumn{4}{|l|}{ Vertical analysis } \\
\hline SNMP & $32 \pm 2$ & 49 & 44 \\
\hline FMA & $25 \pm 2$ & 43 & 42 \\
\hline Y-AXIS & $60 \pm 2$ & 69 & 69 \\
\hline \multicolumn{4}{|l|}{ Dental analysis } \\
\hline UI-SN & $102 \pm 4$ & 104 & 96 \\
\hline IMPA & $87 \pm 3$ & 98 & 85 \\
\hline II & $125-135$ & 128 & 140 \\
\hline UI-NA & 22 & 26 & 7 \\
\hline UI-NA (mm) & $4 \pm 2$ & 4 & -3 \\
\hline LI-NB & 25 & 42 & 25 \\
\hline LI-NB (mm) & $4 \pm 2$ & 12 & 6 \\
\hline $\begin{array}{l}\text { Holdaway } \\
\text { ratio }\end{array}$ & $1: 1$ & $6: 1$ & $6: 1$ \\
\hline \multicolumn{4}{|l|}{$\begin{array}{l}\text { Soft tissue } \\
\text { analysis }\end{array}$} \\
\hline S-plane & $0 \pm 2$ & +5 & +1 \\
\hline Z-angle & $76 \pm 5$ & 52 & 75 \\
\hline $\begin{array}{l}\text { Nasolabial } \\
\text { angle }\end{array}$ & $90-110$ & 112 & 118 \\
\hline
\end{tabular}




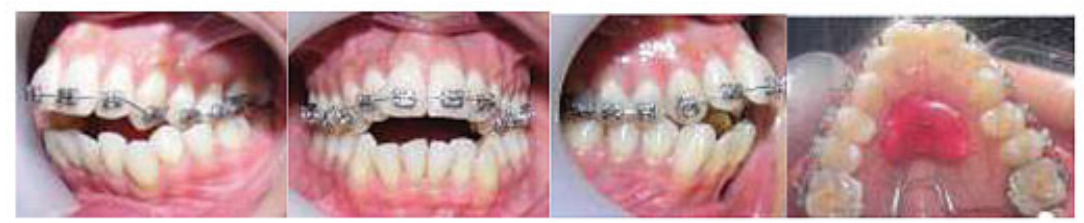

A.

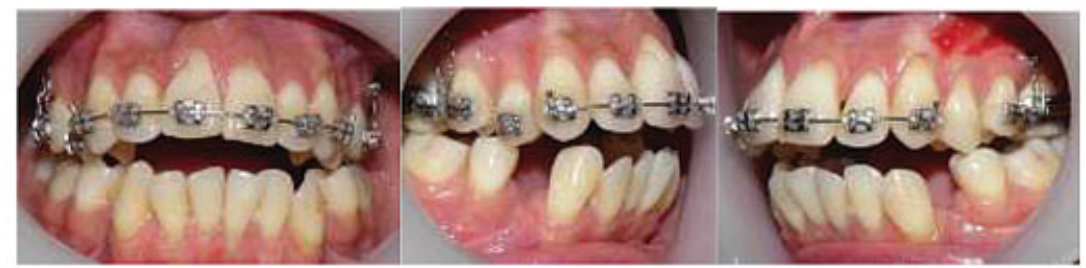

B.
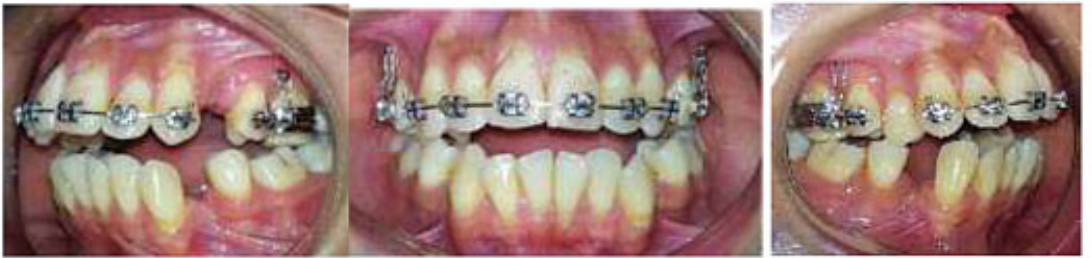

C.

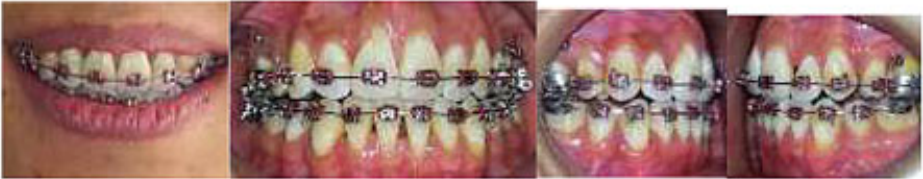

D.

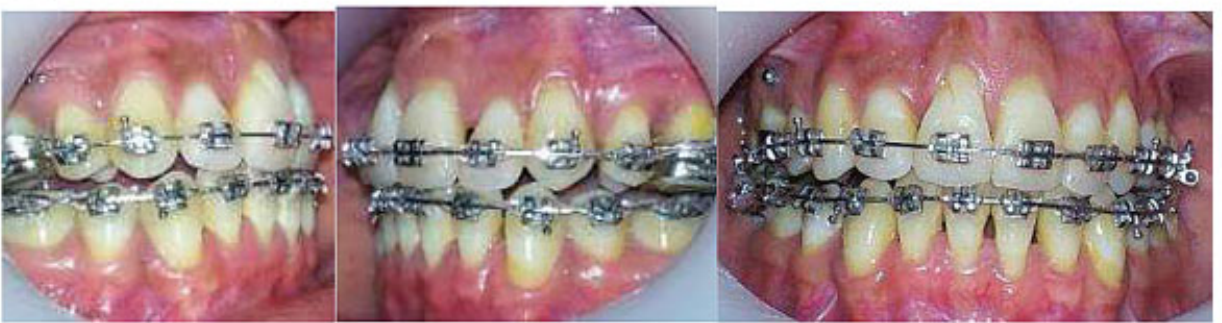

E.

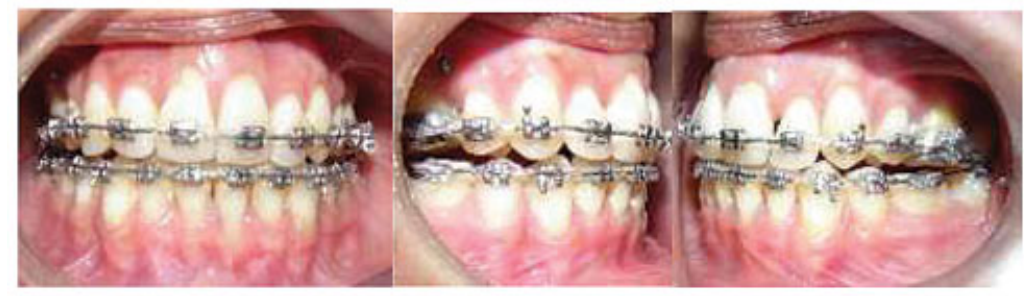

F.

Fig. 4 Progress images (0-24 month treatment). (A) first visit, banding, and bonding. (B) At 7 months of treatment. (C) At 8 months of treatment. (D) At 17 months of treatment. (E) At 18 months of treatment. (F) At 19 months of treatment. 

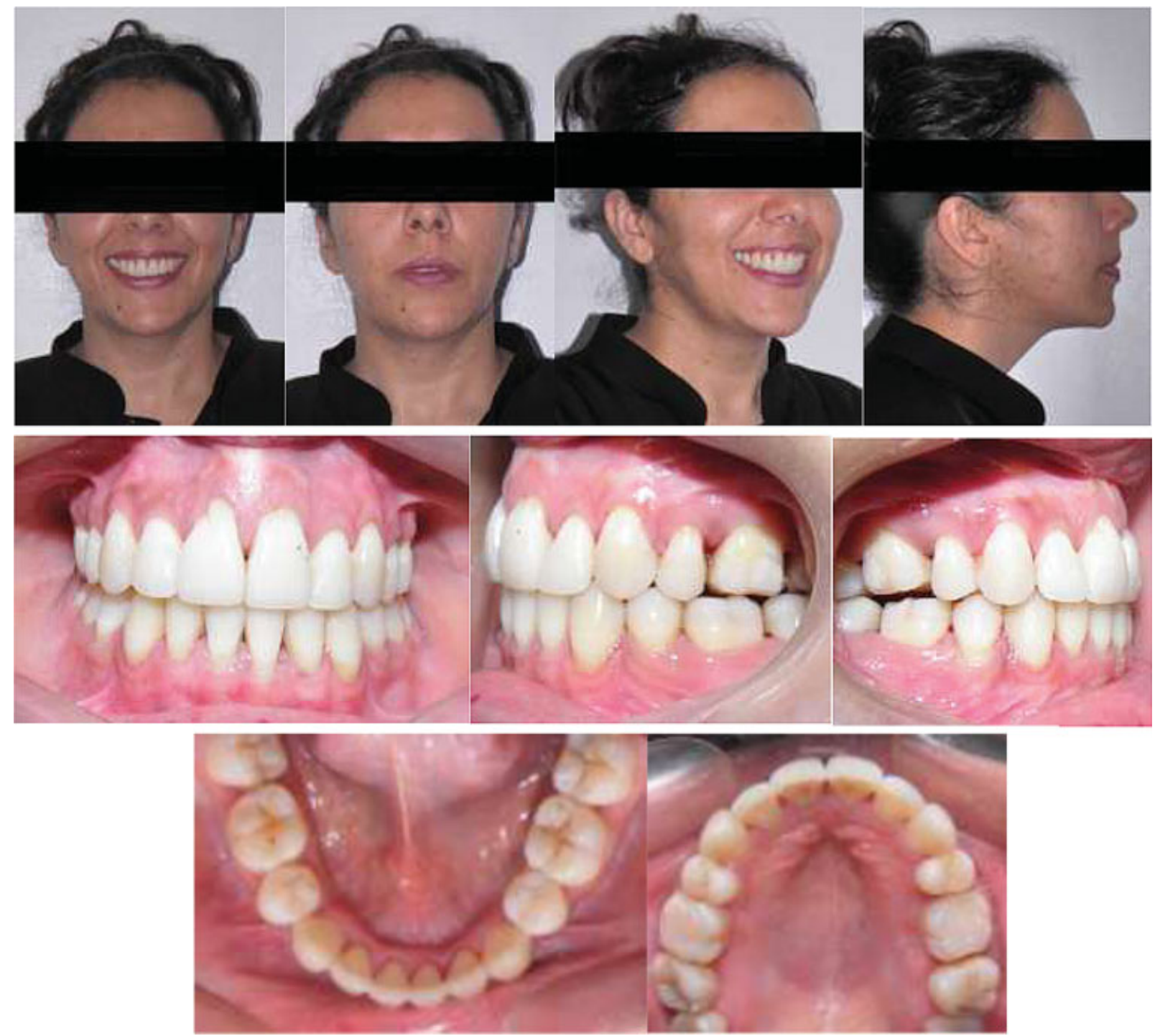

Fig. 5 Post-treatment images.

establish a stable occlusal relationship, that is, Class I incisors, canines and molar, ${ }^{8}$ correct open bites and create an ideal overjet and overbite, ${ }^{9}$ relieve crowding in both arches, ${ }^{10}$ and correct the midline deviation.

\section{Treatment Alternatives}

To achieve the above objectives, two plans were discussed with the patient in the treatment planning conference. Plan A was surgical maxillary impaction, LeFort I osteotomy (segmented 3-piece) combined with fixed orthodontic treatment including extraction of all first premolars. Plan B was maxillary molars intrusion with help of TADs and bite blocks (composite buttons), placement of a transpalatal arch (to control side effects of TADs, that is, buccal tipping of molars), combined with fixed orthodontic treatment including extraction of first premolars in both jaws. Plan B was accepted by the patient. A retention plan was discussed in advance.

\section{Treatment Progress}

At the onset of treatment, the patient was referred to a periodontist for consultation and addressed the issue of a gingival recession on anterior teeth. The patient was classified with stage I, grade A periodontitis. It was decided to use minimum orthodontic forces during treatment to prevent further damage to the periodontium. In addition, the use of an interdental brush and routine scaling to keep existing periodontal pockets clean was advised to the patient. Bands were placed on the maxillary first molars and an impression has done for a transpalatal arch fabrication in a laboratory. Clearance of $2 \mathrm{~mm}$ was kept between arch and palate and the patient was instructed to do tongue exercises, which helped in the correction of tongue trust habit and produced maxillary molar intrusion forces ( - Fig. 4). Pre-adjusted $0.022 \times 0.028$ " slot straight wire MBT prescription brackets were bonded in the upper arch and 0.016 MNiTi archwires were used for the initial leveling using segmental arch mechanics. Composite 

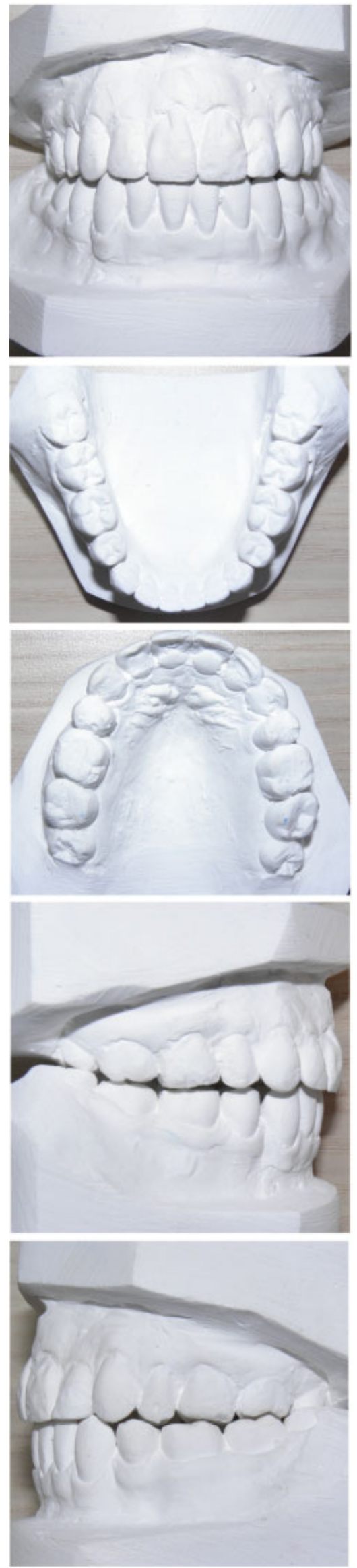

Fig. 6 Post-treatment dental models.

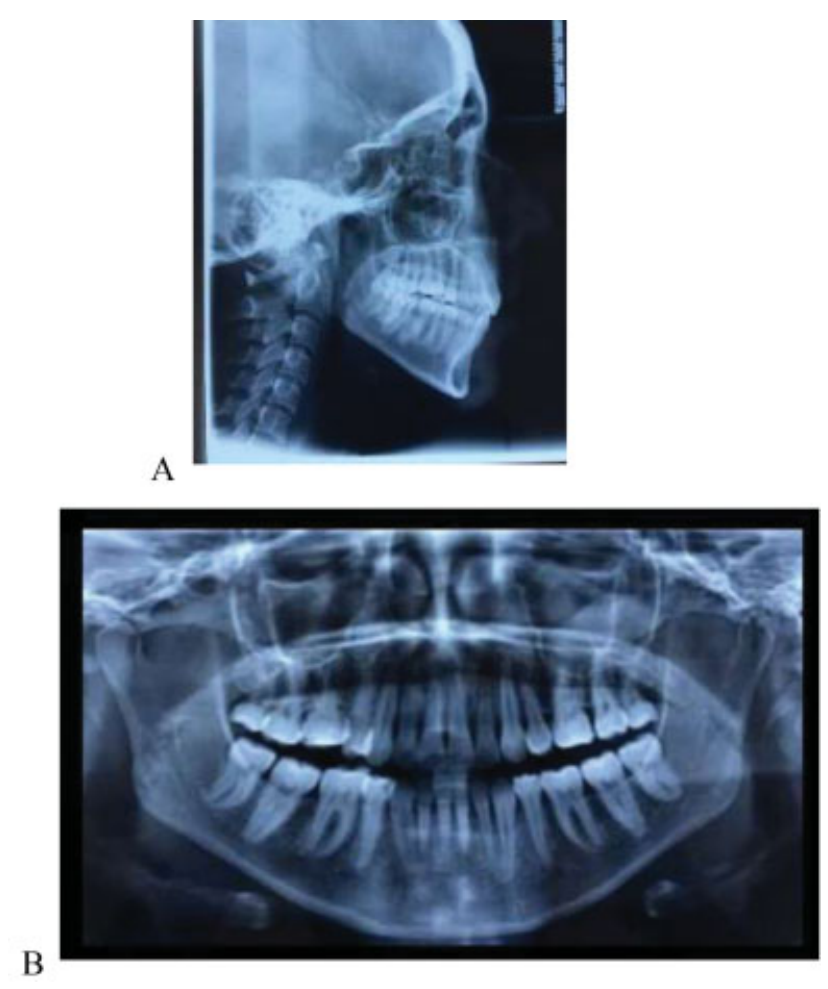

Fig. 7 Post-treatment panoramic (A) and cephalometric (B) radiographs.

buttons were placed on occlusal surface upper first molars. TADs were inserted between maxillary second premolars and first molars and activated on the same visit. Once $3.5 \mathrm{~mm}$ of intrusion was achieved (in reference to upper first premolars), extraction of all first premolars was done. Lower bonding was done and occlusal buttons were shifted to upper second molars and removed from upper first molars. On completion of the alignment, the canine retraction was started on $17 \times 25$ SS wire. Finally, occlusal buttons were shifted to lower third molars. A unique experiment was performed instead of extracting all wisdom teeth, the intrusion of all third molars was attempted with help of composite buttons. Asymmetric implant activation was done in every visit on the left side (roots of molars on the left side are close to sinus floor, thus needs more activation) and on alternate visits at the right side to balance the cant of the occlusal plane. Once we achieved $0 \mathrm{~mm}$ of open bite, midline correction and consolidation of spaces were done. The interproximal reduction was performed on all incisors to correct Bolton's discrepancy and black triangles. Final archwire of size $0.017 \times 0.025$ SS inserted and case finished with prescription of settling elastics (1/4 in, 6 oz.). The total active orthodontic treatment duration was 24 months.

\section{Treatment Results}

Post-treatment records showed that the treatment goals were successfully achieved (-Fig. 5). An esthetic smile arc, good alignment of teeth, and proper occlusal settlement 

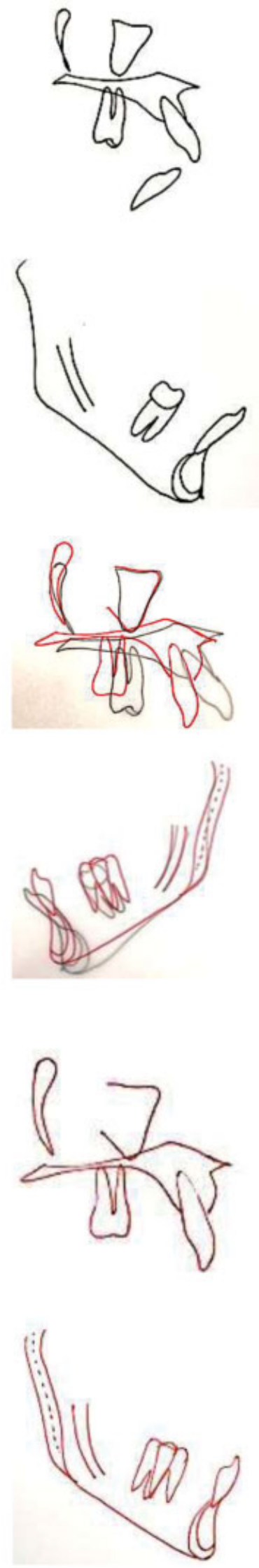

Fig. 8 Pretreatment, post-treatment maxillary, and mandibular tracings and superimpositions.
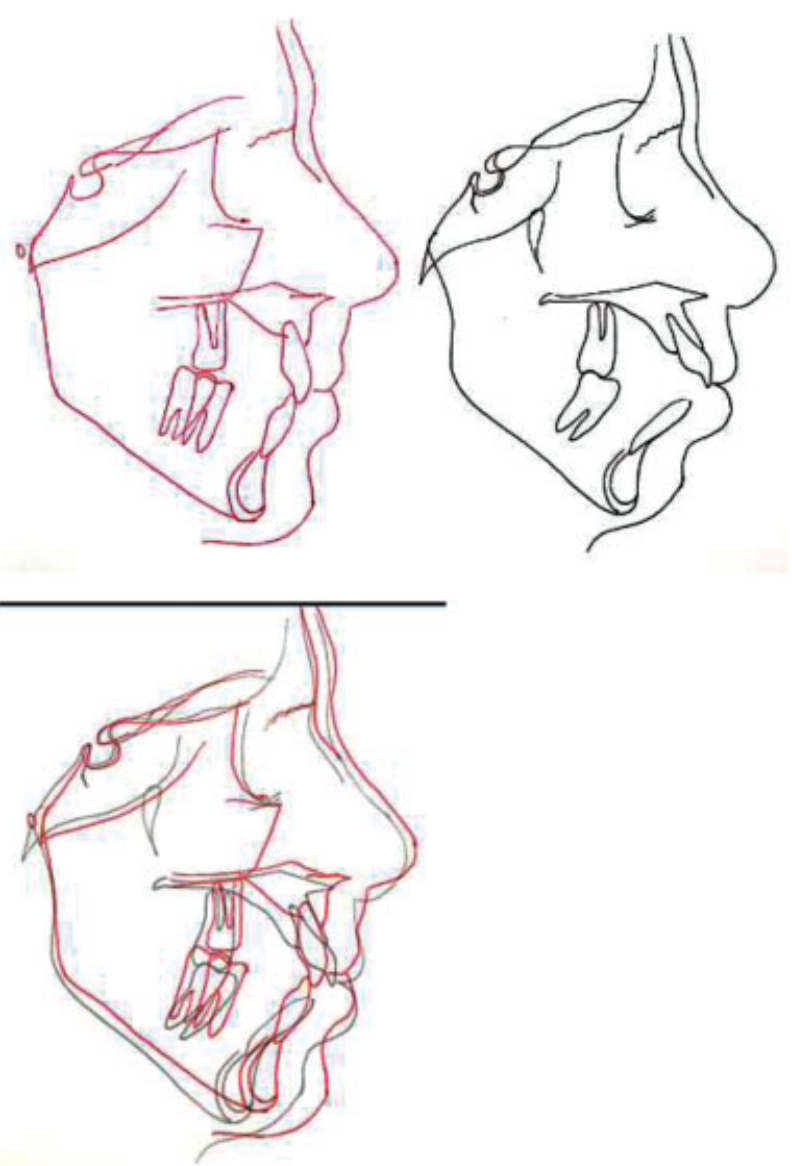

Fig. 9 Pretreatment, post-treatment cephalometric tracings, and superimpositions.

were observed. In addition, marked improvement in the patient's self-esteemed and confidence was observed. The patient's speech was improved among functionality, offering an overall great satisfaction to the patient. The facial photographs showed improvement in esthetics, from convex to straight profile without any facial surgery ( - Fig. 5). Class I incisors, canine and molar relationships were established (-Figs. 5 and $\mathbf{6}$ ), midline deviation and the open bite were corrected with the achievement of ideal overbite and overjet. The upper arch was expanded to eliminate posterior crossbites and to ideal buccal overjet. The panoramic radiograph showed effects of maxillary molar intrusion and satisfactory root parallelism (suggest tooth \# left upper second premolar, left lower canine, and right lower canine roots should go distal) with proper space in between teeth. No significant signs of additional bone or root resorption were noticed ( - Fig. 7). lateral cephalometric analysis (-Table $\mathbf{1}$ ) and superimposition (-Figs. 8 and 9) showed skeletal changes with a forward movement of the mandible (Mac-Pog improved from -19 to -12 ). The intrusion of $5 \mathrm{~mm}$ of maxillary molars and $4 \mathrm{~mm}$ of a forward displacement was noticed on superimposition. Vertical anchorage was maintained throughout 

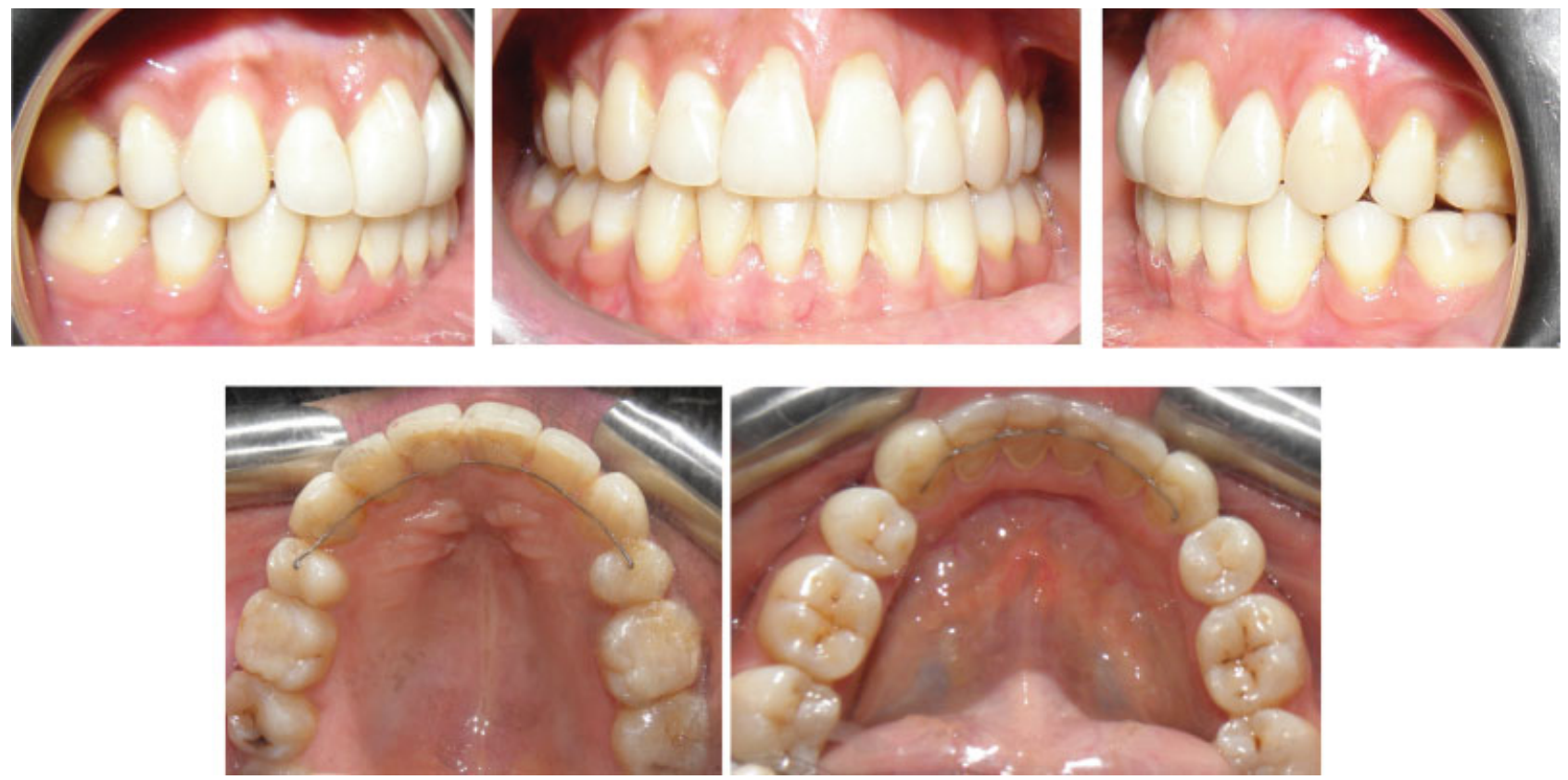

Fig. 10 Follow-up post-treatment 3 years (intraoral images).

treatment and SNMP was reduced from 49 to 44 degrees, showing the effect of mandibular autorotation. Significant retroclination of the maxillary (U1-SN, 104-96) and mandibular incisors (IMPA 98-85) and the interincisal angle changed to 140 degrees was observed compared with the pretreatment angles. Improvement on soft tissue profile was noted (-Figs. 1, 5, and 9).

\section{Case Retention}

A fixed retainer was bonded to the lingual surface of the mandibular and maxillary anterior teeth. Vacuumed formed maxillary retainer was fabricated to secure the stability of open bite treatment.

\section{Case Discussion}

Despite the advanced surgical techniques, many patients with skeletal anterior open bites are not inclined to undergo surgical treatment and are happy to go for less-invasive miniimplants placement. ${ }^{6,9,10}$ The mini implants therapy is designed to control the maxillary vertical growth, thus promoting a counter-clockwise rotation of the mandible. Thus, it helped us to achieve a straight profile in this case without any surgical procedure.

Daguchi et al indicated that intrusion of molar combined with retraction of the anterior segment favors a counter-clockwise rotation of the mandible and improves the stability of the case in contrast to performing only anterior teeth extrusion. ${ }^{11-13}$ Alsafadi et al also stated that the impact of intruding the upper molars is positive and causes a mandibular rotation ranging from $1^{\circ}$ to $4^{\circ}$, thus helping in chin projection and reducing the anterior facial height and the mandibular plane angle. ${ }^{13}$ In the current case, we observed similar effects in our patient's face at end of treatment. In addition, Alsafadi et al indicated maxillary molar intrusion mechanics comes with the challenge of passive extrusion of lower molars. In our case, we have overcome this challenge with the use of composite occlusal buttons, during the finishing stage, on third molars in the mandible. $^{13}$

In general, achieving long-term stability is a key measure of treatment success. According to Goto et al, treatment of open bite involving extractions of teeth cannot provide stability because the retraction of anterior teeth violates the tongue space and have a poor effect on the airway thus disturbing normal function. ${ }^{14}$ On the contrary, others have stated that treatment with extraction allows greater stability because the retraction associated with anchorage loss promotes bite closure. ${ }^{15-18}$ Greenlee et al indicated good stability of both surgical (82\%) and nonsurgical (75\%) treatments of open bite measured by a positive overbite at 12 or more months after treatment. ${ }^{19}$ The results in this clinical case show that extraction treatment with molar intrusion mechanics produces stable results in the treatment of open bite malocclusion (-Fig. 10).

Achieving normal function and habit control is the key to success in open bite management at any age. Habits can cause relapse after orthodontic treatment. ${ }^{20-24}$ It is imperative to counsel the patient on habit control and help them achieve normal function including speech, nasal breathing, and swallowing in addition to dental and facial treatment. 


\section{Conclusions}

Based on available clinical evidence, we suggest that TADs can be used as a valuable tool to intrude molars including wisdom teeth, and help correct the skeletal open-bite with good control without buccal tipping.

\section{Funding \\ None. \\ Conflict of Interest \\ None declared.}

\section{References}

1 Espeland L, Dowling PA, Mobarak KA, Stenvik A. Three-year stability of open-bite correction by 1-piece maxillary osteotomy. Am J Orthod Dentofacial Orthop 2008;134(01):60-66

2 Subtelny JD, Sakuda M. Openbite: Diagnosis and treatment. Am J Orthod 1964;50:337-358

3 Sugawara J, Baik UB, Umemori M, et al. Treatment and posttreatment dentoalveolar changes following intrusion of mandibular molars with application of a skeletal anchorage system (SAS) for open bite correction. Int J Adult Orthodon Orthognath Surg 2002; 17(04):243-253

4 Cabrera MdeC, Cabrera CAG, de Freitas KM, Janson G, de Freitas MR. Lateral open bite: treatment and stability. Am J Orthod Dentofacial Orthop 2010;137(05):701-711

5 Melsen B, McNamara JA Jr, Hoenie DC. The effect of bite-blocks with and without repelling magnets studied histomorphometrically in the rhesus monkey (Macaca mulatta). Am J Orthod Dentofacial Orthop 1995;108(05):500-509

6 Park YC, Lee HA, Choi NC, Kim DH. Open bite correction by intrusion of posterior teeth with miniscrews. Angle Orthod 2008;78(04):699-710

7 Stuani MBS, Stuani AS, Stuani AS. Modified Thurow appliance: a clinical alternative for correcting skeletal open bite. Am J Orthod Dentofacial Orthop 2005;128(01):118-125

8 Lawry DM, Heggie AA, Crawford EC, Ruljancich MK. A review of the management of anterior open bite malocclusion. Aust Orthod J 1990;11(03):147-160

9 Denny JM, Weiskircher MA, Dorminey JC. Anterior open bite and overjet treated with camouflage therapy. Am J Orthod Dentofacial Orthop 2007;131(05):670-678

10 Nielsen IL. Vertical malocclusions: etiology, development, diagnosis and some aspects of treatment. Angle Orthod 1991;61(04): 247-260
11 Deguchi T, Kurosaka H, Oikawa H, et al. Comparison of orthodontic treatment outcomes in adults with skeletal open bite between conventional edgewise treatment and implant-anchored orthodontics. Am J Orthod Dentofacial Orthop 2011;139(4, Suppl) S60-S68

12 Scheffler NR, Proffit WR, Phillips C. Outcomes and stability in patients with anterior open bite and long anterior face height treated with temporary anchorage devices and a maxillary intrusion splint. Am J Orthod Dentofacial Orthop 2014;146(05): 594-602

13 Alsafadi AS, Alabdullah MM, Saltaji H, Abdo A, Youssef M. Effect of molar intrusion with temporary anchorage devices in patients with anterior open bite: a systematic review. Prog Orthod 2016; $17: 9$

14 Goto S, Boyd RL, lizuka T. Case report: nonsurgical treatment of an adult with severe anterior open bite. Angle Orthod 1994;64(04): 311-318

15 Janson G, Valarelli FP, Henriques JF, de Freitas MR, Cançado RH. Stability of anterior open bite nonextraction treatment in the permanent dentition. Am J Orthod Dentofacial Orthop 2003;124 (03):265-276, quiz 340

16 Chang YI, Moon SC. Cephalometric evaluation of the anterior open bite treatment. Am J Orthod Dentofacial Orthop 1999;115(01):29-38

17 Vaden JL. The vertical dimension: the "low-angle" patient. World J Orthod 2005;6(02):115-124

18 Janson G, Valarelli FP, Beltrão RTS, de Freitas MR, Henriques JF. Stability of anterior open-bite extraction and nonextraction treatment in the permanent dentition. Am J Orthod Dentofacial Orthop 2006;129(06):768-774

19 Greenlee GM, Huang GJ, Chen SS, Chen J, Koepsell T, Hujoel P. Stability of treatment for anterior open-bite malocclusion: a metaanalysis. Am J Orthod Dentofacial Orthop 2011;139(02):154-169

20 Cozza P, Baccetti T, Franchi L, Mucedero M, Polimeni A. Sucking habits and facial hyperdivergency as risk factors for anterior open bite in the mixed dentition. Am J Orthod Dentofacial Orthop 2005; 128(04):517-519

21 Heimer MV, Tornisiello Katz CR, Rosenblatt A. Non-nutritive sucking habits, dental malocclusions, and facial morphology in Brazilian children: a longitudinal study. Eur J Orthod 2008;30(06):580-585

22 Speidel TM, Isaacson RJ, Worms FW. Tongue-thrust therapy and anterior dental open-bite. A review of new facial growth data. Am J Orthod 1972;62(03):287-295

23 Urzal V, Braga AC, Ferreira AP. Oral habits as risk factors for anterior open bite in the deciduous and mixed dentition - crosssectional study. Eur J Paediatr Dent 2013;14(04):299-302

24 Dixit UB, Shetty RM. Comparison of soft-tissue, dental, and skeletal characteristics in children with and without tongue thrusting habit. Contemp Clin Dent 2013;4(01):2-6. Doi: 10.4103/0976-237X.111585 